\title{
Making the UK more Resilient to Age-Structural Change and Longevity: Translating Academic Evidence into Policy
}

\author{
Sarah Harper ${ }^{1}$
}

Published online: 2 November 2016

(C) Springer Science+Business Media Dordrecht 2016

The UK is in an historically unique period. During the $20^{\text {th }}$ Century life expectancy gradually increased and the population slowly aged. Increases in life expectancy are driven by changing mortality rates and in particular the current decline in death rates amongst those over 65 is leading to an increase in the number and proportion of adults at very old ages. Population ageing, or age structural change, is driven primarily by low rates of child-bearing, so that the average age of the population increases as fewer young people enter the population.

As a result not only are individuals living longer, they are doing so within a UK population which is in itself growing older. To grow old in a society where most people are young is fundamentally different from doing so in a society where most people are old (Harper 2016). In demographically young populations, there are high proportions of economically active individuals who may produce the wealth needed to support dependents, old and young. However, these societies may not place much emphasis on the wellbeing of older people as they comprise a small minority of the overall population. Conversely, demographically old populations have a lower proportion of economically active individuals and thus the responsibility of providing for old age dependency may be increasingly fall to the older person themselves. It is likely that the 21 st century will see a continuation of these two distinct but related trends.

In the light of this the UK Government Office for Science commissioned a Foresight Review on the Ageing of the UK Population. A multi-disciplinary Expert Committee of British academics [https://www.gov.uk/government/groups/ageing-society-lead-expertgroup] was appointed, and over the next two and a half years extensive demographic projections and modelling over $100 \mathrm{~h}$ of expert meetings and 22 scientific evidence reviews were undertaken, [https://www.gov.uk/government/collections/future-ofageing\#evidence-reviews] exploring the multi-faceted impact of the UK's age-

Sarah Harper

sarah.harper@ageing.ox.ac.uk

1 Oxford Institute of Population Ageing, University of Oxford, Oxford, UK 
structural change. The Academic Committee determined to assess the impact of both the increase in the number and proportion of older people and the increase in the average age of the population. These two demographic trends - increasing longevity and age structural change - will have major and interrelated impacts on UK society.

The societal risks for ageing societies are well known (Lee and Mason 2010). This shift from predominantly young to predominantly older populations raises concerns over the ability of nations to finance the social security and long term health and social care which are required to support a growing number and percentage of older dependents, at a time when the number and percentage of those who are economically active is declining. There are also concerns about the ability to reconfigure health and long term care provision. A third challenge is around the reconfiguration of social institutions to address issues of intragenerational and intergenerational fairness, that is fairness and equity within and between different generations as population age and the support of individual well-being across the life course. Indeed, inequalities in access to resources, health, economic and social, is likely to remain a pressing concern over the coming decades.

Much of the concern around the economic challenge arises from the presumption that future older labour forces will be less productive and less innovative, and that an older population will consume less both with negative consequences for economies. However, in advanced economies at least, new cohorts of highly educated, skilled and increasingly healthy populations are approaching traditional retirement ages, and are increasingly remaining in economic activity - producing, consuming, and paying taxes (Bloom 2011).

The challenge is to make the UK more resilient to these demographic changes. Key questions are how to maintain wellbeing across the life course of these longer lived individuals, and also how to redistribute resources within this new demographic. While currently everyone experiences a decline in mental and physical capacity as they age, this can however be mediated by life style/environment and increasingly in the future by bio-medical intervention, which may delay, though probably not prevent, the onset of this decline. This decline leads to an increased individual need for health and social care, and for a source of late life income, usually in the form of a pension. The ability of an individual to maintain wellbeing is compromised firstly by actual increases in dependency as their mental and physical abilities decline, and secondly by society constructing dependency, through such policies as requiring early withdrawal - retirement -from economic activity on grounds of age while the individual is actually still healthy and productive.

\section{Translating Academic Evidence into Policy}

A key challenge facing the Academic Committee was how to ensure that the message reached the policy makers responsible for future UK policy making in these diverse areas. Working closely with a committed team of civil servants in the Government Office for Science, the following procedure was tried, tested and refined. This was to be "co-design" between academics and policy makers. The question we attempted to address was "How can government make progress in such an interwoven policy area, which in turn is set upon a complex evidence base?" First step was mutual recognition 
of the importance of a scientific approach to evidence gathering. Then came synthesis getting beyond the evidence of what is happening, and into what this means for Government. The evidence was broken down into manageable components, producing key data and implications in an accessible way for policy makers, focussing on the visual (infographic cards) and personal (future personas). This was then presented to over 100 civil servants (policy owners) in a series of cross-government work shop environments, thus allowing policy makers to bring their knowledge of policy making and politics to create a more vivid set of ideas for addressing the challenges and opportunities of an ageing population. Crucial was the buy-in and thus engagement of the centre of Government - in this case the Cabinet Office who report directly to the Prime Minister. This developed into a mutually supportive process: the Central Government trusted that there was a credible plan to develop solutions, policy owners know knew there was a senior audience for their ideas, so both engaged with confidence. Finally this process, which commenced a year before the Report's final publication, culminated in direct feedback to the Academic Committee, who were then able to consider the policy interests and insights gathered from Government's own experts and utilised this knowledge to reframe the issues and explore new perspectives.

\section{The Report}

The result can be found at Government Office for Science (2016). Future of an Ageing Population. Foresight Report, London: Government Office for Science. [https://www. gov.uk/government/collections/future-of-ageing\#project-report]. The focus of evidence was on the increased need for financial and care support for longer lives at a time when there may be fewer workers in the population, and thus the future of work, education, housing, families, connectivity (both physical and digital) and infrastructure all needed to be considered within an ageing population framework. The Foresight Report concluded that the success and resilience of the UK will be determined by the extent to which individuals of all ages cope with increased risk and responsibility for their ever lengthening lives. In particular this combined approach highlighter that issues relating to an ageing population cannot be addressed in silos. Indeed most domestic policy issues will be fundamentally affected by the ageing population. Both policy makers and the academic experts recognised that interventions to make ageing a success are required throughout the life course. And crucially that even within a relatively small country like the UK, there is considerable regional variation and thus a local and regional lens is important for understanding the impact of ageing.

\section{References}

Bloom, D. E. (2011). 7 billion and counting. Science, 333(6042), 562-569.

Government Office for Science. (2016). Future of an Ageing Population, London: Government Office for Science.

Harper, S. (2016). How Population Change Will Transform Our World, Oxford: Oxford University Press.

Lee, R., \& Mason, A. (2010). Some macroeconomic aspects of global population aging. Demography, 47(1), S151-S172. 